\title{
PSYCHIATRIC DISORDER AND PERSONALITY FACTORS ASSOCIATED WITH SUICIDE IN OLDER PEOPLE: A DESCRIPTIVE AND CASE- CONTROL STUDY
}

\author{
DANIEL HARWOOD $^{1 *}$, KEITH HAWTON ${ }^{2}$, TONY HOPE ${ }^{3}$ AND ROBIN JACOBY ${ }^{4}$ \\ ${ }^{1}$ Clinical Research Fellow, Section of Old Age Psychiatry, University of Oxford Department of Psychiatry, Warneford \\ Hospital, Oxford, UK \\ ${ }^{2}$ Professor of Psychiatry, Centre for Suicide Research, University of Oxford Department of Psychiatry, Warneford \\ Hospital, Oxford, UK \\ ${ }^{3}$ Reader in Medicine and Honorary Consultant Psychiatrist, Section of Old Age Psychiatry, University of Oxford \\ Department of Psychiatry, Warneford Hospital, Oxford, UK \\ ${ }^{4}$ Professor of Old Age Psychiatry, University of Oxford Department of Psychiatry, Warneford Hospital, Oxford, UK
}

\begin{abstract}
Objective. To determine the rates of psychiatric disorder and personality variables in a sample of older people who had committed suicide and to compare the rates in a subgroup of this sample with those in a control group of people who died from natural causes.

Design. Descriptive psychological autopsy study, including interviews with informants, of psychiatric and personality factors in 100 suicides in older people. Case-control study using subgroup of 54 cases and matched control group.

Setting. Four counties and one large urban area in central England, UK.

Subjects. Individuals 60 years old and over at the time of death who had died between 1 January 1995 and 1 May 1998, and whose deaths had received a coroner's verdict of suicide (or an open or accidental verdict, where the circumstances of death indicated probable suicide). The control group was an age-and sex-matched sample of people dying through natural causes in the same time period.

Main outcome measures. ICD-10 psychiatric disorder, personality disorder and trait accentuation.

Main results. Seventy-seven per cent of the suicide sample had a psychiatric disorder at the time of death, most often depression $(63 \%)$. Personality disorder or personality trait accentuation was present in $44 \%$, with anankastic or anxious traits the most frequent. Depression, personality disorder, and personality trait accentuation emerged as predictors of suicide in the case-control analysis.

Conclusion. Personality factors, as well as depression, are important risk factors for suicide in older people. Copyright (C) 2001 John Wiley \& Sons, Ltd.
\end{abstract}

KEY WORDS - suicide; elderly; psychiatric disorder; personality

\section{INTRODUCTION}

Studies of suicide in older people have consistently found that over half of those who commit suicide after the age of 65 years are suffering from a depressive disorder at the time of death (Barraclough, 1971; Conwell et al., 1991, 1996; Henriksson et al., 1995). There are less consist-

* Correspondence to: Dr D. Harwood, Consultant in Old Age Psychiatry, Isle of Wight Healthcare Trust, 4 Shide Road, Newport, Isle of Wight, PO30 1YQ. Tel: +44-1983-525244; Fax: +44-1983-529843. ent data on the association of other psychiatric disorders with suicide in the elderly. High rates of alcohol abuse have been found in North American and Finnish studies (Conwell et al., 1991, 1996; Henriksson et al., 1995), but not in the UK (Barraclough, 1971). Margo and Finkel (1990) hypothesise that early dementia may be a risk factor for suicide, but rates of dementia in psychological autopsy studies are usually low; Henriksson et al. (1995) found a rate of $5 \%$ of 'organic disorders' in their series. However, mild dementia may be difficult to identify in a 
retrospective interview. Personality factors in suicide in older people have received limited research attention, but personality disorders seem to be less frequent in older suicide victims than in younger age groups (Henriksson et al., 1995). Preliminary research (Duberstein et al., 1994; Duberstein, 1995) has shown a link between suicide in old age and rigid, emotionally restricted personality traits (low 'openness to experience'), in contrast with the high impulsivity scores found in younger suicide victims.

We aimed to carry out a study of psychiatric disorder in older suicide victims using psychological autopsy interviews with informants. Such interviews are vital for the identification of psychiatric and personality variables in suicide research (Hawton et al., 1998a). We hoped to build on existing work by collecting detailed data on personality and mild cognitive impairment, and by using a control group in an attempt to determine whether risk factors for suicide demonstrated in case series still hold when compared to an age- and sex-matched sample of non-suicide deaths. Our hypotheses were that the prevalence of depression, mild cognitive impairment, personality disorder and significant maladaptive personality traits [particularly anankastic (obsessional) and dependent types] would be higher in the suicide group.

\section{METHOD}

There were two parts to this study:

(1) A descriptive study of the prevalence of psychiatric disorder, personality disorder, and significant maladaptive personality traits in a case series of older people dying through suicide.

(2) A case-control study comparing the rates of these disorders in a subgroup of this sample with those in an age and sex matched control group of people who had died through natural causes.

The study was approved by the Oxford Psychiatric Research Ethics Committee and the Birmingham and Solihull Research Ethics Committee.

\section{Descriptive study}

Data was collected on a consecutive series of people aged 60 years and over who had died by suicide in Berkshire, Buckinghamshire, Northamptonshire, Oxfordshire and Birmingham between 1 January 1995 and 1 May 1998. Sources of information used were coroners' inquest notes, GP case-notes, psychiatric records and interviews with informants.

Details of all inquests in this age group in which a verdict of suicide was made were collected by regular visits to the coroner's offices. As some deaths receiving open or accidental death verdicts are likely to be suicides (O'Donnell and Farmer, 1995; Salib, 1997) information was also collected for cases receiving these verdicts where circumstances suggested suicide; for example, death following overdose. Summaries of each of these cases were written by the first author and circulated to the other authors. Each author decided whether the case was a 'probable suicide' and hence for inclusion in the study. Information influencing our decision towards inclusion in the study included records of statements or actions indicating suicidal intent, and the absence of alternative reasons for a particular act (e.g. a large overdose was judged to be a suicidal act unless there was evidence to the contrary). If three or more of us agreed that the case was a probable suicide it was included in the study. If there was a greater level of disagreement, the decision as to whether or not to include the case was arrived at by consensus after discussion.

Information recorded for all cases covered demographic details, mode and circumstances of death, and psychiatric history documented in the statements of relatives, doctors, and other witnesses. Information on past psychiatric and medical history was obtained from the GP notes. Psychiatric case-notes were examined if the deceased had been in contact with psychiatric services in the year before death.

An interview was conducted with one or more key informants. The first informant to be contacted was the person who was in closest contact with the subject in the year before death. If the GP of the deceased agreed, a letter inviting participation in the study was sent to the potential informant. If no reply had been received after three weeks, a reminder was sent, followed by a telephone call to the informant after a further two weeks if still no reply had been forthcoming. Because of differences in Research Ethics Committee requirements, no 
such phone calls were made to potential informants for Birmingham subjects. If the first informant contacted declined to take part in the study, another informant was approached.

\section{Case-control study}

The control group was a sample of people who had died through natural causes in hospital, individually age- and sex-matched with subjects in the suicide group. We identified control subjects for only 54 of the 100 suicide group subjects in the time available for the study. Controls were identified from two Oxford, and two Birmingham general hospitals. Hospital administrators provided lists of deaths in each hospital, from which we identified patients of the same sex, and who had died at an age within 30 months either side of the age at death of a subject in the suicide group. The patient on a list whose age at death was closest to the matched suicide subject was the first choice control subject. The medical notes of potential controls were scrutinised for details of each patient's GP, next of kin, and medical history. The subsequent recruitment procedure was identical to that for the suicide group.

\section{The informant interview}

We aimed to conduct interviews between 6 and 12 months after the subject's death, usually in the informant's home. Interviews lasted about three hours (range one and a half to seven hours) and were usually completed in one sitting.

The semi-structured part of the interview covered the antecedents to the death, and a detailed family and personal history. Personality variables were assessed using the ICD-10 version of the Personality Assessment Schedule (PAS) (Tyrer et al., 1988), which enabled both ICD-10 personality disorders, and personality trait 'accentuation' not meeting the criteria for personality disorder, to be diagnosed.

Psychiatric disorders in the month before death were diagnosed using the Psychiatric Illness Questionnaire, an instrument based on ICD-10 research criteria (WHO, 1993) which has been used in recent British psychological autopsy studies (e.g. Hawton et al., 1998b). Screening questions covering ICD categories of disorder were asked, followed by detailed questions on specific symptoms if the screening questions received positive answers. The short version of the Informant
Questionnaire on Cognitive Decline in the Elderly (IQCODE) (Jorm, 1994) was used to assess cognitive decline before death.

After interview, informants were offered a Bereavement Information Pack (Hill et al., 1997). Four weeks later, a telephone call to the informant clarified any points not clear from the interview and ascertained the impact of the interview on the informant.

For suicide subjects where information was not available from interview, 'best guess' ICD-10 psychiatric diagnoses were made using information from the inquest notes and medical records. In these subjects there was too little information to diagnose personality disorders.

When an informant interview was carried out, the interviewer $(\mathrm{DH})$ made ICD-10 diagnoses of psychiatric disorder, personality disorder, and personality trait accentuation using information gathered from all sources. A case summary was prepared and circulated to the other three authors who each made a judgement as to the correct ICD10 diagnosis. Disagreements on diagnosis were resolved by discussion and reaching consensus decisions at regular meetings of the investigators.

Where subjects suffered both physical illness and depressive symptoms before death it was often difficult to judge whether a depressive episode was present. To ensure a consistent approach to diagnosis, we took possible depressive symptoms at face value; thus, if a subject was reported to suffer tiredness, this was included as a depressive symptom regardless as to whether it may have been due to physical illness.

\section{Statistical analyses}

Descriptive statistics were used to describe the characteristics of the case series. Comparisons between the suicide and control groups were carried out using conditional logistic regression in order that the matching of the suicide and control groups was taken into account. Univariate conditional logistic regression provides an odds ratio, which in this study is an estimation of the risk of suicide in those with a particular psychiatric risk factor relative to those without it (relative risk). Because conditional logistic regression analyses could not be applied in all cases due to very small numbers in one or other group, comparisons of the proportions in the two groups were also made using the $\chi^{2}$ or Fisher's exact tests. The statistical packages used were SPSS for Windows (version 
6.1.4) for the descriptive statistics and the Egret package (Cytel Software Corporation, 1997) for the logistic regression analyses. With 54 subjects in each group for the case-control study, the smallest statistically significant difference (at the $80 \%$ level) in prevalence the study had the power to detect was a rate of $20 \%$ of a variable in the suicide group and a $1 \%$ rate in the control group.

\section{RESULTS}

\section{Descriptive study of suicide subjects}

One hundred and ninety-five subjects dying by suicide were identified in the study period. Coroner's records were viewed in all cases. A suicide verdict had been recorded in 160 cases $(82.1 \%)$, an open verdict in 27 cases $(13.8 \%)$ and an accidental death verdict in eight cases $(4.1 \%)$. All but two subjects (99\%) were registered with a GP at the time of their death, and we viewed the GP case-notes in $159(82.4 \%)$ of these. Fifty-one subjects had had contact with a psychiatric team in the last year of life, and we examined psychiatric records for $48(94.1 \%)$ of this group. In two cases the coroner advised us not to contact relatives, in 22 cases the GP did not give consent for us to contact relatives, and in 71 cases the potential informant(s) declined to be interviewed or we were unable to contact them. Thus informant interviews were completed in 100 cases $(51.3 \%)$. Figure 1 displays the drop-out at different stages of recruitment in flow diagram form. Table 1 shows the number of suicides and rates of suicide for each county during the study period.

For subjects where informant interviews were completed, in 78 cases a single informant was interviewed, in 20 cases two informants, and in two cases more than two informants. The mean time after the death at which the interview took place was 11 months (range 5-23 months). Ninety-seven $(97 \%)$ of the interviews took place face to face, two interviews were carried out over the telephone and one (with an informant who lived abroad) was completed by postal questionnaire. Ninety interviews took place in the informant's home, five at the informant's place of work, and two at the interviewer's office.

The mean age of the informants for the suicide interviews was 54.9 years (range 23-85), $41 \%$ were male, and $75 \%$ were in contact at least weekly with the subject in the year before death. Children of the deceased were the principal informant in $33 \%$ of cases, friends in $25 \%$, spouses in $17 \%$, siblings in $9 \%$, and other relatives or professionals in $16 \%$ of the sample. The proportions of these characteristics were not statistically significantly different (on $\chi^{2}$ analysis) from those in the group of informants for the suicide sample for whom a matched control was identified.

In a recent British psychological autopsy of suicide in young people (Appleby et al., 1999), the rates of expressed suicidal intent by the subjects and levels of psychiatric contact before death differed in the groups of subjects with and without an interview. These variables might have led to selection bias in the interview group by influencing an informant's availability or willingness to be interviewed. We hypothesised that age, sex, ethnic origin and marital status of the deceased person, a coroner's verdict other than suicide, and history of deliberate self-harm, might also influence whether or not an interview was carried out in our study. We therefore calculated the rates of all these variables in the groups with and without interviews, to ascertain whether any detectable selection bias contributed to the composition of our interview group. No statistically different differences on $\chi^{2}$ analysis were found in the prevalence of these variables between the two groups.

Table 1. Suicide numbers and rates per 1000 population over 60 years old (calculated from 1991 Census data) during the study period according to county or region

\begin{tabular}{lcc}
\hline County/region & No. of suicides & Suicide rate ( per 1000 over 60) \\
\hline Berkshire & 39 & 0.32 \\
Birmingham & 41 & 0.21 \\
Buckinghamshire & 29 & 0.27 \\
Northamptonshire & 46 & 0.42 \\
Oxfordshire & 40 & 0.38 \\
\hline
\end{tabular}


The sociodemographic characteristics of the entire suicide subject sample have already been described (Harwood et al., in press).

One hundred and forty-nine $(76.4 \%)$ of the total suicide sample (cases with and without interviews) and $77 \%$ of the interview sample were assigned a psychiatric diagnosis. There appeared to be no major differences in the prevalence of the main psychiatric diagnoses between the interviewed and non-interviewed suicide groups. Further discussion of results will refer to the group with interview data.

The prevalence of psychiatric disorders and personality variables in the suicide subjects with interviews is shown in Table 2. More than one psychiatric disorder was present in 15 subjects $(15.0 \%)$. Personality disorders were found in 16 $(16.0 \%)$ subjects and personality 'trait accentuation' without personality disorder in an additional $28(28 \%)$, with anankastic, anxious, and dependent traits the most frequent.

The prevalence of psychiatric disorder was slightly higher in those over 74 years of age $(82.1 \%)$ compared with those aged between 60 and 74 years $(73.8 \%)$. The rates of personality disorder were slightly lower in those over 74 years of age $(10.3 \%)$ than in younger subjects $(19.7 \%)$. There were no gender differences in rates of personality disorder; $15.2 \%$ of women and $16.4 \%$ of men were diagnosed as having a personality disorder, although a slightly higher proportion of women than men were diagnosed as having a psychiatric disorder $(81.8 \%$ compared with $73.8 \%)$. Fifteen $(93.8 \%)$ out of 16 of those with a personality disorder had a co-morbid psychiatric disorder.

\section{Case-control study}

Fifty-four of the 100 subjects with interview data were paired with an age and sex matched natural cause death control subject (see Fig. 1). The prevalence of several variables in the suicide subjects with interview data with and without a matched control subject were examined to look for possible selection bias. The mean ages of the two groups were similar ( 72 and 74 years for the interview and non-interview groups, respectively) and there were no statistically significant differences in the proportions of the following variables in the two groups: gender, marital status, non-UK ethnic origin, coroner's verdict other than suicide, presence of previous self-harm attempts, suicidal communication in year before death, past psychiatric contact, or contact with psychiatric services at the time of death.

Table 3 compares with characteristics of the informants for the suicide and control groups. The informants for the control group were of similar age and sex distribution compared with the

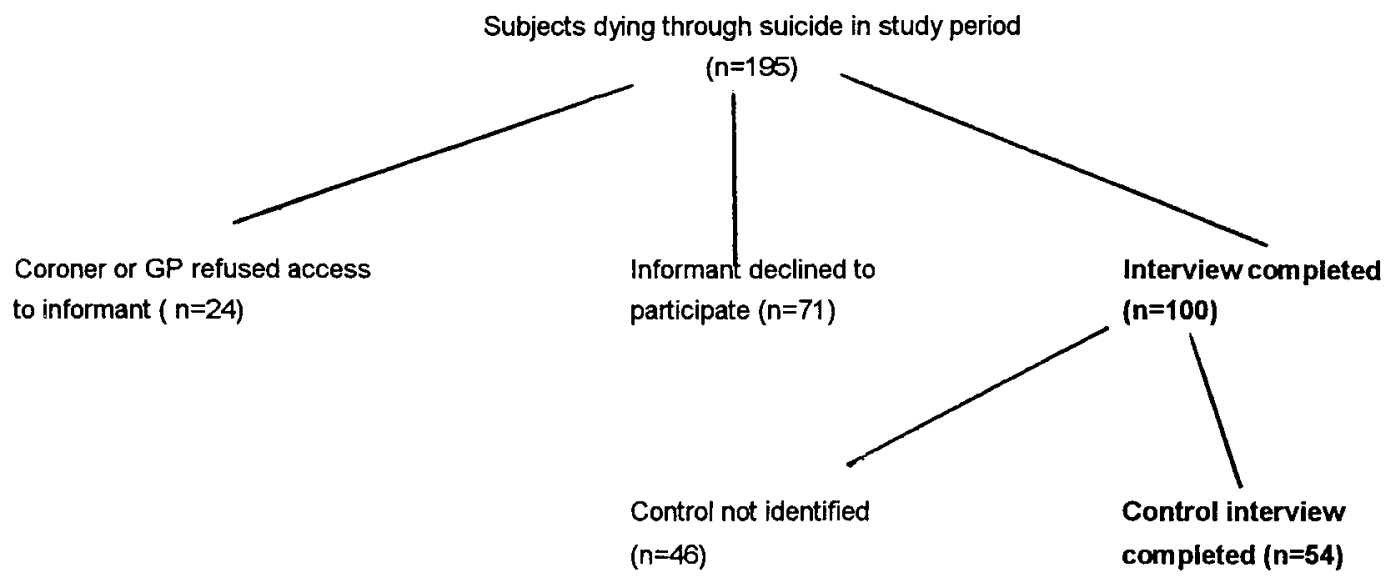

Fig. 1. Flow diagram of recruitment of suicide subjects 
informants for the matched suicide group. They were, however, more likely to be spouses and less likely to be friends. The frequency of contact of the informant with the deceased in the year before death was greater in the control group.

The prevalence of psychiatric disorder and personality variables in the suicide and control groups is shown in Table 4. The following psychiatric diagnoses emerged as predictors of being a member of the suicide group in the casecontrol analysis: depression (odds ratio 4.0), personality disorder (odds ratio 4.0) and personality trait accentuation (odds ratio 4.7). Trait accentuation of the anankastic and anxious types was more frequent in the suicide group than the control group. Rates of delirium and dementia were statistically significantly higher in the control group. Psychiatric disorder (any type) did not

Table 2. Descriptive study: psychiatric disorder and personality factors in the 100 suicide subjects with an informant interview

\begin{tabular}{lr}
\hline ICD-10 code and diagnosis & $N$ \\
\hline Psychiatric disorder & \\
One or more psychiatric disorder* & 77 \\
F00-F09 Dementia & 4 \\
Other organic disorders & 7 \\
F10-F19 Alcohol misuse & 5 \\
Other substance misuse & 5 \\
F20-29 Schizophrenia and related disorders & 4 \\
F30-F39 Bipolar affective disorder-depressed & 4 \\
Depressive episodes† & 59 \\
F40-69 Adjustment, somatoform, and sexual disorders & 5 \\
Personality disorder & \\
F60-69, one or more personality disorder* & 16 \\
Anankastic & 4 \\
Dissocial & 4 \\
Histrionic & 4 \\
Other & 3 \\
Mixed personality disorders & 5 \\
Personality trait accentuation* & \\
Anankastic & 19 \\
Anxious & 13 \\
Dependent & 9 \\
Histrionic & 6 \\
Other & 44 \\
Personality disorder or trait accentuation & \\
\hline
\end{tabular}

*More than one psychiatric disorder was diagnosed in 15 subjects, more than one specific personality disorder in three subjects, and accentuation of more than personality trait in four subjects.

$†$ Depression was mild in 12 cases, moderate in 14 cases, and severe in 22 cases, with 11 cases of unspecified severity. emerge as a predictor of suicide. However, excluding subjects with delirium from the analysis, the presence of any other psychiatric disorder did emerge as a risk factor [odds ratio $4.0(95 \%$ C.I. $1.5-10.7), p=0.006]$. No differences in the prevalence of delusional disorder or alcohol or substance abuse were detected, but the rates of these disorders in both groups were very low.

\section{DISCUSSION}

This study is the largest psychological autopsy study of suicide in older people that has been reported world-wide. Multiple sources of information were used: we examined GP and psychiatric case-notes in addition to coroners' records, and performed interviews with key informants. Ours is the first British survey of suicide in the elderly to include informant interviews since Barraclough's (1971) description of a sub-group of older suicide victims from his landmark psychological autopsy study of suicide in all age groups (Barraclough et al., 1974). The recent British coroners' record based studies of Cattell (1988) and Cattell and Jolley (1995) included only cases where a verdict of suicide was returned. In order to make ours a comprehensive sample of suicides, we also included deaths receiving open and accidental death verdicts where these seemed to be probable suicides.

\section{Methodological issues}

The only previous psychological autopsy study of suicide in older people to use a control group of deceased subjects (Miller, 1978) did not examine psychiatric risk factors. We chose a natural cause death control group as we wanted to study the risk factors for suicide in the general older population. The use of deceased control groups in suicide research has been advocated on the grounds that it minimizes asymmetry in data collection techniques between suicide and control groups (Clark and Horton-Deutsch, 1992). There were methodological difficulties with our control group. The mode of case identification and sources of information available for suicides and controls were different. The coroners' notes contained more information and a longer list of potential informants than the hospital case-notes used as the initial data source for the control group. Additionally, only 14 (26\%) of the suicide group were married compared with $25(46 \%)$ of the controls $\left(p=0.03, \chi^{2}=4.86\right)$. These 
two factors may have led to the higher proportion of spouses acting as informants in the control group, and the greater number of friends interviewed in the suicide group. Chronic physical illness may have been over-represented in the natural death control group. Hospital inpatients have high rates of cognitive impairment and depression (Bowler et al., 1994), leading to high rates of these diagnoses in the control group. Lastly, possible differences in the grief reaction between the informants in the suicide and control groups (Barrett and Scott, 1990) might have influenced the way in which the informants responded to interview questions.

The main limitation of this study is the low participation rate of potential informants. Similarly low rates were noted in other recent English psychological autopsy studies (Hawton et al., 1998b; Appleby et al., 1999), in contrast with higher participation rates in studies of suicide in older people from the USA (e.g. Conwell et al., 1996) and Finland (Henriksson et al., 1995). These international differences may reflect more assertive recruitment procedures, which would not be allowed by UK Research Ethics Committees, or different societal attitudes towards participation in psychiatric research in these countries. The low participation rate led to difficulties recruiting informants for the control group, and the casecontrol study was of smaller size than we had hoped. It thus lacked the statistical power to detect small differences in prevalence of potential predictors of suicide.
There was the possibility of selection bias at two levels. First, the cases in the suicide group with informant interviews may have been unrepresentative of the suicide group as a whole. We did not find any of the variables which we postulated could have led to selection bias to be associated with participation in the study. However, it is possible that access to an informant may have been related to factors which we could not test for due to lack of information on the non-interviewed subjects. For example, people with personality disorders, schizophrenia or alcohol dependence, may have been less likely to have informants available, biasing results of the case-control analysis for these disorders towards the null hypothesis. Second, the suicide subjects for whom a matched control was identified may not have been representative of the interviewed suicide group, but we found no differences in the rates of different variables in the interviewed sub-group of suicide subjects for whom a control was identified, compared with the sub-group without a control.

The diagnosis of psychiatric disorder in psychological autopsy studies has been well validated (Brent et al., 1993; Kelly and Mann, 1996). Blinding of the interviewer as to whether a subject was a suicide or control was obviously impossible, so interviewer bias cannot be ruled out. However, the instruments used for assessing personality and psychiatric variables were standardised and structured, and the same screening questions were asked for all informants in both suicide and control groups.

Table 3. Comparison of characteristics of informants used for psychological autopsy interviews in suicide and control groups for case-control study

\begin{tabular}{|c|c|c|c|c|c|}
\hline & \multicolumn{2}{|c|}{ Suicides $(N=54)$} & \multicolumn{2}{|c|}{ Controls $(N=54)$} & \multirow[t]{2}{*}{ Statistical analysis } \\
\hline & $N$ & $(\%)$ & $N$ & $(\%)$ & \\
\hline Age (mean) & 55.5 & & 59.6 & & $p=0.21^{*}$ \\
\hline Male gender & 22 & $(40.7)$ & 17.0 & $(31.4)$ & $\chi^{2}=1.0, p=0.32$ \\
\hline \multicolumn{6}{|l|}{ Relationship of main informant to deceased } \\
\hline Spouse & 7 & $(13.0)$ & 22 & $(40.7)$ & $\chi^{2}=10.6, p=0.001$ \\
\hline Child & 19 & $(35.2)$ & 21 & $(38.9)$ & $\chi^{2}=0.2, p=0.69$ \\
\hline Sibling & 6 & $(11.1)$ & 5 & $(9.3)$ & $\chi^{2}=0.1, p=0.75$ \\
\hline Friend & 15 & $(27.8)$ & 5 & $(9.3)$ & $\chi^{2}=6.1, p=0.01$ \\
\hline Other & 7 & $(13.0)$ & 1 & (1.9) & $p=0.03 \dagger$ \\
\hline $\begin{array}{l}\text { Frequency of contact with deceased in year before death } \\
\text { less frequently than weekly }\end{array}$ & 12 & $(22.3)$ & 3 & $(5.6)$ & $\chi^{2}=6.3, p=0.01$ \\
\hline
\end{tabular}

*Student's $t$-test.

$\dagger$ †isher's exact test. 


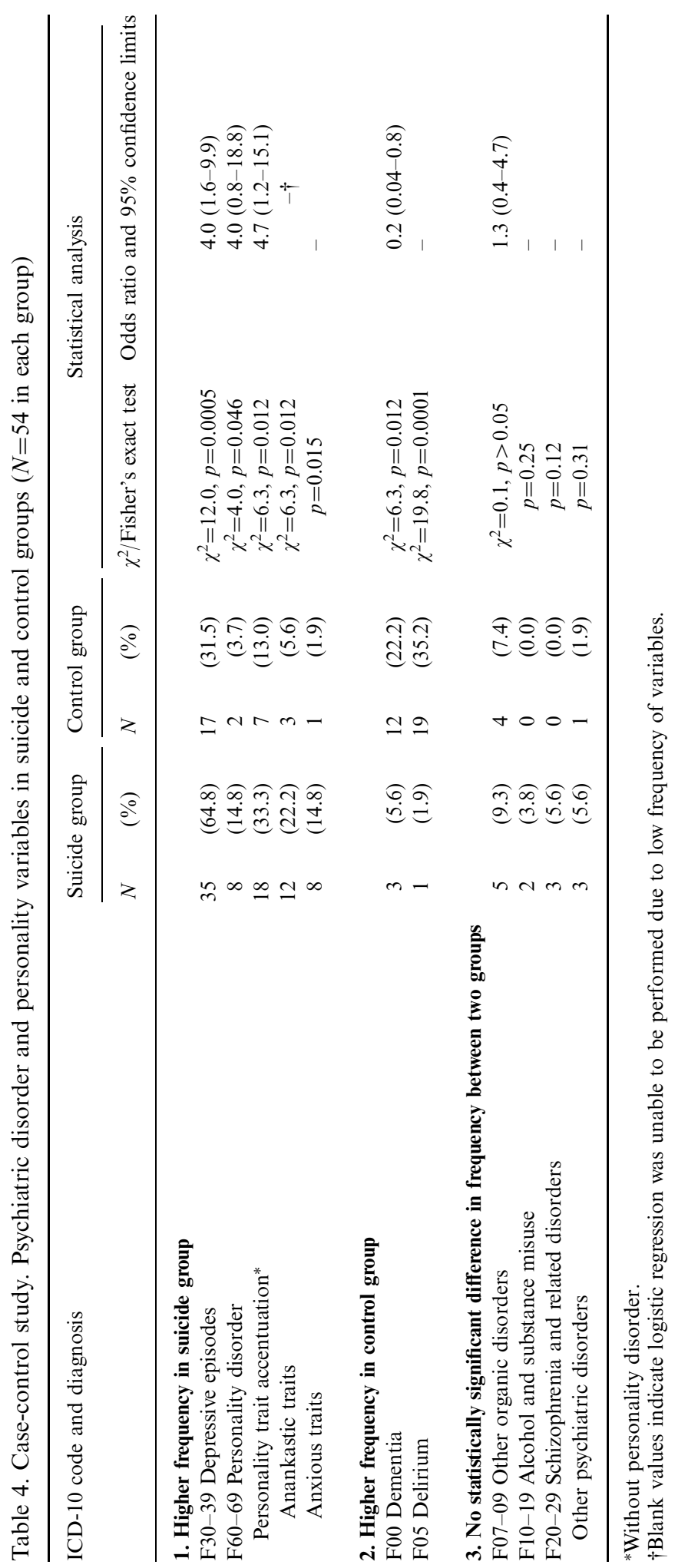


Using an informant interview to diagnose psychiatric disorder in older people presented special problems. First, it could be difficult to ascertain whether somatic symptoms were due to depression or physical illness. We included somatic symptoms in the check-lists used to diagnose depression, regardless of whether the subject had co-existent physical illness, enabling a consistent approach to diagnosis in both suicide subjects and controls. This approach may have led us to overdiagnose depression in both groups, but it is likely that any over-diagnosis would have occurred more in the physically ill control group. Problems leading to possible under-diagnosis of psychiatric illness in the control group include the 'masking' of psychiatric symptoms by physical illness or delirium, and informants in this group perhaps being more liable to attribute distress to physical rather than psychiatric illness.

\section{Psychiatric disorder}

Over three-quarters $(77 \%)$ of the suicide sample for whom informant interviews were performed had a psychiatric disorder at the time of death. Psychiatric disorder did not emerge as a risk factor for suicide when compared to the control group due to the high rates of delirium and dementia in the control group. The clearest finding of the study is the high rate of depression found in the suicide sample; nearly two-thirds of the individuals in the suicide group with interviews were suffering from a depressive disorder at the time of death. This figure is lower than the $87 \%$ found by Barraclough (1971). It is, however, similar to the rates of 64 $71 \%$ found in most other studies of older suicides (Conwell et al., 1991, 1996; Henriksson et al., 1995), with the exception of Carney et al. (1994) who found a rate of only $36 \%$ for major depression in their study from the USA. Despite the high rate $(31 \%)$ of depressive episodes in the control group, depression was the only psychiatric disorder found to be a predictor of suicide in the comparison of suicide and control groups.

In the interviewed suicide sample, the rates of dementia $(4.0 \%)$ and other cognitive impairments $(6.0 \%)$ are similar to rates found in population surveys of cognitive impairment in older people (e.g. Copeland et al., 1992), despite our use of a sensitive instrument for detecting early cognitive decline. The high rate of dementia in the control group makes comparison with this group problematic. The relation between dementia and suicide is likely to be complex. It is possible that mild dementia is a risk factor for suicide (Margo and Finkel, 1990) but that the risk declines as deterioration in executive function and increased supervision from carers make a completed suicide less likely (Conwell, 1995). Our study suggests that although cognitive decline may be one factor contributing to suicide in certain individuals, it is not of major importance as a risk factor at a population level.

The rate of alcohol abuse in our interviewed suicide sample $(5.0 \%)$ was much lower than the $25-47 \%$ found in recent studies in the USA (Conwell et al., 1996) and in Finland (Henriksson et al., 1995). This may reflect real international differences in the prevalence of alcohol abuse in older people, but the rate may also be higher in these countries because of the greater prevalence of shooting as a method of self-injury (Shah and De, 1998). Impulsive suicidal acts in the context of alcohol use are more likely to have a fatal outcome if shooting is used as the method of self-harm.

The low rates of alcohol and substance abuse, and of schizophrenia, contrast with the higher rates of these disorders found in recent UK studies of younger suicide victims (Appleby et al., 1999) and studies of suicide in all age groups (Foster et al., 1997; Vassilas and Morgan, 1998). As discussed earlier, the apparently low rates of alcohol dependence and schizophrenia may have been due to the reduced likelihood of people with these disorders having an available informant.

Multiple psychiatric disorders occurred in $15 \%$ of our suicide group with interviews, a figure lower than the $32 \%$ found in a recent UK study of younger suicide victims (Appleby et al., 1999) and the $31 \%$ reported in a recent study from Northern Ireland of suicide in all age groups (Foster et al., 1997).

Over $20 \%$ of the suicide sample had no evidence of psychiatric disorder at the time of death. This may have been because the study methodology was not sensitive enough to detect all psychiatric disorders, or it may reflect the inadequacy of ICD-10 criteria for diagnosing psychiatric disorders in older people. Of course, this group may contain people for whom suicide was a rational decision in the face of severe life problems. The characteristics of the subjects with no diagnosed psychiatric disorder will be described in a separate report. 


\section{Personality factors}

The rate of personality disorder in the suicide group $(16 \%)$ is similar to the rate of $14 \%$ found in the Finnish series (Henriksson et al., 1995), but lower than the rates of around $30-40 \%$ found in studies of younger suicides (Appleby et al., 1999; Foster et al., 1997; Henriksson et al., 1995). Dissocial or borderline disorders in particular are more prevalent in younger suicide victims. Our finding of an association of suicide in older people with anankastic (obsessional) and anxious personality traits may have parallels in recent work from the USA. Using the NEO-PR, a dimensional method of measuring personality, older suicide victims have been shown to be more likely to have low scores on the 'openness to experience' sub-scale than younger suicide victims, who display higher levels of impulsivity (Duberstein et al., 1994; Duberstein, 1995). The low openness to experience domain, characterised by constricted affect, lack of adaptability, and cognitive rigidity, overlaps to some extent with ICD-10 anankastic personality traits. It is plausible that older people who are less adaptable will cope poorly with the inevitable changes that ageing brings, and may be at increased risk of suicide. Nearly all the suicide subjects with a personality disorder diagnosis had a comorbid psychiatric disorder, suggesting that suicide in an older person with personality difficulties is rare without a co-existent psychiatric illness.

\section{CONCLUSIONS}

Our study confirms depression as the most important psychiatric risk factor in suicide in older people in the UK. Other psychiatric disorders may be important as contributory factors to suicide in individuals, but this study provides no evidence for the hypotheses that alcohol abuse, schizophrenia, and dementia are major predictors of suicide in the elderly. Personality factors, particularly anankastic (obsessional) traits, appear to have an important role in suicide in older people. These findings underline the importance of an adequate assessment of personality, preferably obtaining information from a relative or friend, when evaluating suicide risk in older people. Clinicians need also to be aware that different personality factors may be associated with suicide risk in younger and older people. Future research will need to address the specific risk factors associated with suicide in depressed elderly patients, and extend our knowledge of the role of personality dimensions in suicidal behaviour in older people. Clearly, psychiatric and personality variables are only one set of risk factors for suicide. The role of life events, physical illness, and social isolation as risk factors for suicide in older people will be discussed in a future report.

\section{KEY POINTS}

- Depression is confirmed as the most important psychiatric risk factor for suicide in older people.

- Abnormal personality traits, especially of the anankastic (obsessional) and anxious types, are also predictors of suicide in the elderly. This highlights the importance of detailed assessment of premorbid personality when assessing suicide risk in older people.

- Although alcohol abuse, psychotic disorders, and cognitive impairment may contribute to suicide in some individuals, this study provides no evidence that these disorders are important risk factors for suicide in older people in general.

- The major limitations of this study were the low participation rate of potential informants in psychological autopsy interviews, and the fact that the control group was not representative of the general older population because of high rates of dementia and delirium in this group.

\section{ACKNOWLEDGEMENTS}

This work was supported by a MRC (UK) Project Grant awarded to Professor Robin Jacoby, Professor Keith Hawton, and Dr Tony Hope. We would like to thank the coroners, coroners' officers, general practitioners and psychiatrists, who allowed us access to their records and enabled this study to take place. Helen Doll provided invaluable statistical advice. We would especially like to thank the relatives and others who were interviewed as part of this study. 


\section{REFERENCES}

Appleby L, Cooper J, Amos T, Faragher B. 1999. Psychological autopsy of suicides by people aged under 35. Br J Psychiatry 175: 168-174.

Barraclough BM. 1971. Suicide in the elderly. $B r J$ Psychiatry (special suppl. 6): 87-97.

Barraclough B, Bunch J, Nelson B, Sainsbury P. 1974. A hundred cases of suicide: clinical aspects. $\mathrm{Br} J$ Psychiatry 125: 355-373.

Barrett TW, Scott TB. 1990. Suicide bereavement and recovery patterns compared with nonsuicide bereavement patterns. Suicide Life Threat Behav 20: 1-15.

Bowler C, Boyle A, Branford M, Cooper SA, Harper R, Lindesay J. 1994. Detection of psychiatric disorders in elderly medical inpatients. Age Ageing 23: 307-311.

Brent D, Perper J, Moritz G, Allman CJ, Roth C, Schweers J, Balach L. 1993. The validity of diagnoses obtained through the psychological autopsy procedure in adolescent suicide victims: use of family history. Acta Psychiatr Scand 87: 118-122.

Carney SS, Rich CL, Burke PA, Fowler RC. 1994. Suicide over 60: The San Diego study. J Am Geriatr Soc 42: 174-180.

Cattell HR. 1988. Elderly suicide in London: an analysis of coroners' inquests. Int J Geriatr Psychiatry 3: 251261.

Cattell H, Jolley DJ. 1995. One hundred cases of suicide in elderly people. Br J Psychiatry 166: 451-457.

Clark D, Horton-Deutsch SL. 1992. Assessment in absentia: the value of the psychological autopsy method for studying antecedents of suicide and predicting future suicides. In Assessment and Prediction of Suicide, Maris RW, Berman AL, Maltsberger JT, Yufit RI (eds). Guilford: New York.

Conwell Y. 1995. Dementia. Crisis 16: 5-6.

Conwell Y, Olsen K, Caine ED, Flannery C. 1991. Suicide in later life: psychological autopsy findings. Int Psychogeriatr 3: 59-66.

Conwell Y, Duberstein PR, Cox C, Herrmann J, Forbes NT, Caine ED. 1996. Relationships of age and axis I diagnoses in victims of completed suicide: a psychological autopsy study. Am J Psychiatry 153: 10011008.

Copeland JRM, Davidson IA, Dewey ME, Gilmore C, Larkin BA, McWilliam C. 1992. Alzheimer's disease, other dementias, depression and pseudo-dementia: incidence and three-year outcome in Liverpool. $\mathrm{Br} J$ Psychiatry 161: 230-239.

Cytel Software Corporation. 1997. Egret: Reference Manual. Cytel Software Corporation: Cambridge, MA.

Duberstein PR. 1995. Openness to experience and completed suicide across the second half of life. Int Psychogeriatr 7: 183-198.
Duberstein PR, Conwell Y, Caine ED. 1994. Age differences in the personality characteristics of suicide completers: preliminary findings from a psychological autopsy study. Psychiatry 57: 213-224.

Foster T, Gillespie K, McLelland R. 1997. Mental disorders and suicide in Northern Ireland. $\mathrm{Br} J$ Psychiatry 170: 447-452.

Harwood DMJ, Hawton K, Hope T, Jacoby R. Suicide in older people: mode of death, demographic factors, and medical contact before death in one hundred and ninety-five cases. Int J Geriatr Psychiatry, 15: 736-743

Hawton K, Appleby L, Platt S, Foster T, Malmberg A, Simkin S. 1998a. The psychological autopsy approach to studying suicide: a review of methodological issues. $J$ Affect Disord 50: 269-276.

Hawton K, Simkin S, Malmberg A. 1998b. Suicide and Stress in Farmers. The Stationery Office: London.

Henriksson MM, Marttunen MJ, Isometsä ET, Heikkinen ME, Aro HM, Kuoppasalmi KI, Lonnqvist JK. 1995. Mental disorders in elderly suicide. Int Psychogeriatr 7: 275-286.

Hill K, Hawton K, Malmberg A, Simkin S. 1997. Bereavement Information Pack. For those Bereaved Through Suicide or other Sudden Death. Royal College of Psychiatrists: London.

Jorm AF. 1994. A short form of the Informant Questionnaire on Cognitive Decline in the Elderly (IQCODE): development and cross-validation. Psychol Med 24: 145-153.

Kelly TM, Mann JJ. 1996. Validity of DSM-IIIR diagnosis by psychological autopsy: a comparison with clinical ante-mortem diagnosis. Acta Psychiatr Scand 94: 337-343.

Margo UM, Finkel JA. 1990. Early dementia as a risk factor for suicide. Hosp Community Psychiatry 41: 676-678.

Miller M. 1978. Geriatric suicide: the Arizona study. Gerontologist 18: 488-495.

O'Donnell I, Farmer R. 1995. The limitations of official suicide statistics. Br J Psychiatry 166: 458-461.

Salib E. 1997. Coroner's verdicts in the elderly: a suicide or an open verdict? Int J Geriatr Psychiatry 12: 481483.

Shah A, De T. 1998. Suicide and the elderly. Int $J$ Psychiatry Clin Pract 2: 3-17.

Tyrer P, Alexander J, Ferguson B. 1988. Personality Assessment Schedule (PAS). In Personality Disorder: Diagnosis, Management, and Course, Tyrer P (ed.). Butterworth/Wright: London.

Vassilas CA, Morgan HG. 1997. Suicide in Avon. Life stress, alcohol misuse and use of services. $\mathrm{Br} J$ Psychiatry 170: 453-455.

WHO. 1993. The ICD-10 Classification of Mental and Behavioural Disorders. Diagnostic Criteria for Research. World Health Organisation: Geneva. 